\title{
LOS PROYECTOS DE LEY DEL PROCEDIMIENTO ADMINISTRATIVO COMÚN DE LAS ADMINISTRACIONES PÚBLICAS Y DE RÉGIMEN JURÍDICO DEL SECTOR PÚBLICO: UNA PRIMERA EVALUACIÓN
}

\author{
Juan Alfonso Santamaría Pastor \\ Catedrático de Derecho Administrativo de la Facultad de Derecho de la Universidad Complutense de Madrid \\ jsantamaria@gomezacebo-pombo.com
}

I. LA INICIATIVA. II. RASGOS GENERALES DE LOS PROYECTOS. A) Cuestiones sistemáticas y competenciales. B) El contenido de los proyectos. 1. La óptica dominante: la mejora del funcionamiento interno de la Administración. 2. Escaso alcance innovador. 3. Preocupación abrumadora por la Administración electrónica. III. LAS INNOVACIONES. A) Errores, ambigüedades, incertidumbres. B) Reformas desafortunadas. 1. Régimen de identificación de los ciudadanos. 2. Deber de conocer el código de identificación. 3. Plazos fijados en horas. 4. Deber de comunicación electrónica. 5. Poderes y comparecencias electrónicas. 6 . Supuestos generales de producción de silencio negativo. 7. Obligaciones de colaboración de los ciudadanos. 8. Mutación del instituto de las actuaciones previas. 9. Generalización del sistema de clemencia. IV. LAS DEFICIENCIAS NO CORREGIDAS. A) Las reformas cruciales nunca abordadas. 1. La precisión del régimen de la caducidad de los procedimientos iniciados de oficio. 2. El eterno problema de las "notificaciones del mes de agosto". 3. El engañoso efecto liberalizador de las declaraciones responsables y de las actividades comunicadas. 4. El problema de los actos dictados en ejecución de reglamentos anulados. 5. El inmovilismo del sistema de recursos. 6. La asignatura pendiente de la confidencialidad. B) Otras cuestiones de menor entidad. 1. Las relaciones de procedimientos. 2. Los tratamientos desigualitarios. 3. La interdicción de la reformatio in pejus. 4. La prohibición de abstención. V. CONCLUSIÓN.

\section{LA INICIATIVA}

Fue un motivo de sorpresa la noticia, que circuló a primeros del presente año 2015, de haberse sometido a información pública dos anteproyectos de ley capitales, que afectaban al núcleo mismo del ordenamiento administrativo'. Casi nadie los esperaba ni los había reclamado, siendo el producto estricto de una iniciativa gubernamental; y pasaron desapercibidos para la generalidad del mundo académico y de otros numerosos colectivos jurídicos, que solo tuvieron conocimiento de su existencia cuando ya había transcurrido el plazo de la exposición pública. Tampoco les prestaron excesiva atención quienes fueron informados de la iniciativa, siempre a través de canales paralelos, considerándolos como un típico gesto de la hiperactividad política que suele desencadenarse en los momentos crepusculares de cada legislatura, y estimando que probablemente no llegarían a convertirse en derecho positivo; es muy difícil —aunque nada es imposible cuando existe voluntad política y una cierta capacidad de gestión- que dos textos de esta envergadura puedan llegar a ser aprobados en un año que parlamentariamente

1 Se trata, obviamente de los anteproyectos (hoy ya proyectos) de Ley del Procedimiento Administrativo Común de las Administraciones Públicas (que designaré, en lo sucesivo, como PLPAC) y de Régimen Jurídico del Sector Público (en adelante, PLRJSP). Tras los informes del Consejo General del Poder Judicial y del Consejo de Estado, los proyectos fueron presentados al Congreso de los Diputados el 11 de mayo de 2015 y publicados en el Boletín Oficial de la Cámara Núm. A-155-1 de 18 de mayo. 
consta solo de nueve meses², incluidos los períodos vacacionales, y más aún cuando la agenda del Congreso de los Diputados presenta hoy un abultamiento inusual 3 .

Sin embargo, la aprobación de los proyectos por el Consejo de Ministros, su publicación en el Boletín Oficial del Congreso del día 18 de mayo y las manifestaciones de los portavoces gubernamentales acerca de la voluntad política de culminar su debate y aprobación, han constituido una llamada a la realidad y al análisis urgente de estos textos. Mi larga experiencia como servidor parlamentario me hace albergar más que serias dudas acerca de la posibilidad real de que estas iniciativas lleguen a las páginas del Boletín Oficial del Estado antes de las próximas elecciones generales; pero la mera eventualidad de que este pronóstico resulte desacertado, o, en otro caso, de que el texto pueda volver a renacer con un nuevo gobierno, sea del color que sea, nos ponen a todos ante el imperativo de colaborar en la mejora de unas leyes que remueven las aguas profundas de todos los juristas de Derecho público que profesionalmente navegamos en ellas; o, al menos, a expresar nuestro parecer sobre ellas de modo anticipado.

En términos muy generales, los dos textos que hemos de analizar merecen una valoración positiva desde una perspectiva formal. Se coincida o no con sus contenidos, es obligado reconocer que nos hallamos ante dos documentos elaborados con minuciosidad y técnica jurídica depurada, que revelan un intenso trabajo de fondo: no se trata, como ha sucedido en otras muchas ocasiones, de proyectos redactados apresuradamente, sin cuidado alguno por el estilo y la claridad, y trufados de ocurrencias, sino de iniciativas muy estimables y meritorias.

Sería insólito, sin embargo, que los proyectos no ofrecieran puntos débiles y aspectos mejorables; y es tarea de quienes no hemos participado en su elaboración advertirlos, por si pudieran ser corregidos en el debate parlamentario o, quizá, en la próxima legislatura. Por ello, el presente análisis se centrará, exclusivamente, en las facetas negativas que estos textos presentan: no se intenta, obviamente, destacar los aspectos de los proyectos merecedores de alabanza, que los tienen. Limitarse a resaltar los defectos de los textos no debe entenderse, pues, como una descalificación global de los mismos; es, a mi entender, la mejor forma de cooperar lealmente a su éxito. A lo largo de mi vida profesional me he visto obligado a redactar borradores de múltiples disposiciones, y me consta la extrema dificultad de la tarea; y, aunque sea innecesario, no quisiera dejar de hacer constar mi respeto por un producto tan elaborado y, por supuesto, hacia sus autores.

Antes de comenzar el examen de los textos solo desearía añadir dos advertencias. En primer lugar, que, puesto que la preocupación de los proyectos se centra preferentemente en la mejora del funcionamiento interno de la Administración —como inmediatamente advertiré-, el análisis partirá de la óptica opuesta, la propia de los ciudadanos que se relacionan con la Administración y la de los derechos y garantías que parece obligado conferirles. Y, en segundo lugar, que aunque muchas de las críticas que se expondrán son compartidas por la generalidad no solo del mundo académico, sino también del profesional, hay otras numerosas que surgen de preocupaciones muy personales e individuales, que no aspiro a que sean asumidas.

\section{RASGOS GENERALES DE LOS PROYECTOS}

\section{A) Cuestiones sistemáticas y competenciales}

Los trámites previos a la remisión de los proyectos a las Cortes Generales (principalmente, en los extensos dictámenes del Consejo General del Poder Judicial y del Consejo de Estado) han sido el escenario de un arduo debate acerca de la escisión de la materia a regular en dos textos formalmente diferenciados, de su respectivo contenido y, como no, sobre los títulos competenciales que el Estado invoca para amparar estas nuevas regulaciones.

No prestaré una atención especial a estas cuestiones, cuya importancia — me parece — se ha magnificado.

1. Creo acertada, por meras razones de claridad, la separación en dos textos de la temática comprensiva del régimen jurídico de las Administraciones Públicas, en la que la competencia estatal se limita al esta-

2 La convocatoria de elecciones generales, supuesto que la legislatura ha de finalizar no más tarde del 20 de noviembre de 2015 , deberá efectuarse, como muy tarde, el 27 de septiembre anterior, de acuerdo con lo dispuesto en el artículo 42.1 de la Ley Orgánica del Régimen Electoral General.

3 A fecha de hoy (2 de junio de 2015) se hallan en trámite, en la llamada Cámara baja, un total de 49 proyectos de ley, muchos de ellos de gran extensión y trascendencia: entre otros, lo de Asistencia Jurídica Gratuita; de Código Penal Militar; de Jurisdicción Voluntaria; de Denominaciones de Origen; de Patentes; del Personal de la Policía Nacional; del Sistema Nacional de Protección Civil; de Auditoría de Cuentas; de Ordenación, Supervisión y Solvencia de las Entidades Aseguradoras y Reaseguradoras; de reforma de las Leyes de Enjuiciamiento Civil y de la Ley Orgánica del Poder Judicial; de Recuperación y Resolución de Entidades de Crédito; del Tercer Sector de Acción Social; del Sistema de la Inspección del Trabajo; de Defensa de la Calidad Alimentaria; de Cooperación Jurídica Internacional en Materia Civil; del Sector Ferroviario; de Carreteras; de Sociedades Laborales y Participadas; y de Seguridad Nacional; todos ellos — salvo los dos últimos- en fase de tramitación anterior a los que se analizan en el presente estudio. 
blecimiento de las bases, y de la relativa al procedimiento administrativo común, sobre la que el Estado ostenta una competencia exclusiva.

2. Pero, en tal caso, resulta cuestionable la regulación en el PLRJSP, y dentro de su Título Preliminar (que, supuestamente, se refiere a las bases del régimen jurídico de las Administraciones), de la responsabilidad patrimonial de las Administraciones, materia sobre la que, en mi opinión, el Estado posee una competencia exclusiva de regulación, en contra de lo que diversos Estatutos de Autonomía disponen. Es cierto que el artículo 1 del PLRJSP distingue nítidamente ambas materias ("las bases del régimen jurídico de las Administraciones Públicas, los principios del sistema de responsabilidad de las Administraciones Públicas y de la potestad sancionadora"); pero me temo que esta sutileza no sea suficiente para hacer frente a la suposición de que, en materia de responsabilidad, las comunidades autónomas pueden ostentar potestades de desarrollo normativo.

3. A esta objeción podría añadirse otra mucho menos trascendente: la separación que se produce, respecto de la responsabilidad y de la potestad sancionadora, entre la regulación de sus aspectos sustantivos (integrados en el PLRJSP) y los procedimentales (que se llevan al PLPAC); lo que es consecuencia de la asunción parcial de las críticas formuladas por el Consejo de Estado a los anteproyectos. Pero esta separación solo ocasiona una relativa incomodidad para quienes en el futuro tengamos que aplicar dos leyes en lugar de una sola, un inconveniente que no parece capital desde ningún punto de vista

4. Tampoco me parece una cuestión crucial (aunque sea un tanto chocante) la extraña mixtura que se produce en el PLRJSP entre los temas generales relativos al régimen jurídico de todas las Administraciones (en su texto, los títulos preliminar y tercero) y la regulación detallada de la organización de la Administración General del Estado (títulos primero y segundo), que se ha hecho encastrando en el Proyecto el total contenido de la vigente Ley 6/1997, de 14 de abril, de Organización y Funcionamiento de la Administración General del Estado, entre otras disposiciones, que se derogan expresamente, además de las numerosas modificaciones a la ley del Gobierno que se introducen en las disposiciones adicionales. No ignoro la utilidad práctica que tiene refundir en un único texto las normas de esta Ley con las hoy dispersas relativas a las sociedades estatales, las fundaciones públicas, los consorcios y los fondos sin personalidad jurídica. Pero es evidente que esta mezcla temática da al PLRJSP un contenido altamente heterogéneo; y quizá hubiera sido preferible extraer de él los mencionados títulos primero y segundo, así como buena parte de las disposiciones adicionales, y limitar su contenido a lo que indica su rótulo, el régimen jurídico organizativo común a todas las Administraciones y a sus relaciones. Pero, en todo caso, insisto, me parece una cuestión secundaria.

5. Y no me referiré apenas a los problemas de orden competencial, a los que los dictámenes ya mencionados de ambos Consejos dan una singular importancia, y a los que la redacción definitiva de los proyectos aportan una solución moderadamente aceptable. De nada serviría, por otra parte, intentar un diseño más afinado de la descripción de los títulos competenciales, dado que estos proyectos, de llegar a ser aprobados, serán objeto de impugnación ante el Tribunal Constitucional con seguridad absoluta; y será la decisión que el Tribunal adopte la que fije definitivamente las reglas de juego. Únicamente quisiera expresar mi desconcierto por la invocación que la disposición final primera, 2, del PLPAC hace al artículo 149.1.14. ${ }^{a}$ de la CE, relativo a la Hacienda general, y al artículo 149.1.13. ${ }^{a}$ (competencia en materia de bases y coordinación de la planificación general de la actividad económica), para amparar la regulación que hace de la iniciativa legislativa y de la potestad para dictar reglamentos; no alcanzo a comprender la conexión entre la materia citada y los títulos constitucionales que se mencionan.

\section{B) El contenido de los proyectos}

Entrando ya en su contenido, tres son, a mi entender, los rasgos más acusados de ambos proyectos.

\section{La óptica dominante: la mejora del funcionamiento interno de la Administración}

El primero, su elaboración desde la óptica dominante del funcionamiento interno de las Administraciones, con una notoria marginación de las relaciones de los ciudadanos con ellas. Esta óptica es prácticamente la única que preside el PLRJSP, que deviene de esta forma en una disposición puramente organizatoria; pero es también prevalente en el PLPAC. Y si no es de extrañar que textos que surgen en el seno de una organización dedicada a mejorar la eficacia y eficiencia de las organizaciones administrativas (me refiero, claro está, al CORA) se preocupen mayoritariamente de resolver los problemas y corregir las disfunciones de éstas, resulta chocante y un tanto censurable que se desentiendan abiertamente de compensar el fortalecimiento de las potestades públicas que 
la Administración ostenta con una mejora de los derechos y medios de garantía de los ciudadanos, que no son especialmente bien tratados.

Es cierto que en el PLPAC se dejan ver algunos “detalles" aislados que no figuran en la normativa hoy vigente y que los ciudadanos agradecerán sin duda, como sucede con la declaración de inhabilidad de los sábados (art. 30.2), la no exigencia, como regla general, de la presentación de documentos originales (art. 28.3), o la aclaración del régimen de ejecutividad de las resoluciones sancionadoras (art. 90.3). Pero estos avances —mínimos, aunque nunca despreciables - se ven ampliamente superados por las innovaciones que endurecen el status jurídico de los ciudadanos, que son muy numerosos y de los que luego daremos cuenta. Por más que no sea grato, es forzoso reconocer que el acervo de garantías de los administrados experimenta, con estos proyectos, un retroceso respecto de la versión original de la Ley 30/1992, pese a los errores e ingenuidades de libro en que ésta incurrió.

\section{Escaso alcance innovador}

La presentación al parlamento de dos textos legales de las dimensiones y trascendencia de éstos podría hacer pensar que introducen novedades capitales en la regulación del procedimiento y del régimen jurídico de las Administraciones; pero su lectura demuestra que no es así. Su apariencia formal es la propia de dos textos refundidos (por supuesto, sin delegación legislativa previa) cuyos preceptos suponen, en ocasiones, amplios desarrollos de normas hoy vigentes (por ejemplo, en el régimen de los convenios y de las relaciones interadministrativas que se contiene en el PLRJSP), pero que en otros muchos casos se limitan a operar modificaciones aisladas, que en ocasiones son casi imperceptibles y de alcance puramente teórico (por ejemplo, la adición de cuatro palabras en el artículo 8.1, párrafo segundo del PLRJSP). Pero toda la regulación es profundamente continuista: no hay un solo replanteamiento en profundidad de ninguna institución vertebral; solo pequeñas reformas, puntualizaciones, aclaraciones y desarrollos de lo que ya está vigente.

Ello sugiere dos reflexiones.

Primera, si no hubiera sido más operativo presentar un proyecto de reformas aisladas a diversos textos legales, acompañado de una amplia delegación para refundirlos. Más operativo y quizá más prudente, porque presentar dos textos-resumen en los que se reproducen mayoritariamente normas en vigor tiene el riesgo de que disposiciones generalmente aceptadas y ya consolidadas en la práctica sean objeto de modificaciones nocivas en el debate parlamentario, fruto de ocurrencias o de enmiendas transaccionales de contenido imprevisible.

Y segunda, la decepción que produce el que los proyectos (principalmente, el PLPAC) no aborden reformas reclamadas unánimemente por la generalidad de la doctrina desde hace muchos años; reformas sencillas, sin coste alguno, que mejorarían intensamente el status de garantías de los ciudadanos sin suponer ningún grave inconveniente para el correcto funcionamiento de las Administraciones Públicas, y que, dicho sea en términos crudamente pragmáticos, ayudarían a la "venta política” de los proyectos ante la opinión pública. Bien al contrario, muchas de las modificaciones que los proyectos introducen se mueven en la línea contraria de una reducción o restricción de aquel conjunto de garantías, sin que supongan ninguna mejora trascendental en la actuación eficaz de la Administración.

\section{3) Preocupación abrumadora por la Administración electrónica}

La tercera nota que llama la atención es, sin duda, mucho menos relevante desde la perspectiva práctica, pero no debe ser silenciada. La incorporación al PLPAC de la Ley 11/2007, de 22 de junio, de Acceso Electrónico de los Ciudadanos a los Servicios Públicos hace que el primero cobre una imagen obsesiva por la temática de la Administración electrónica, que llega a extremos que lindan con lo hilarante. El que el adjetivo “electrónica”, en todas sus variantes, o el adverbio correlativo, se repitan 249 veces en el PLPAC y 101 en el PLRJSP (hasta quince veces en el artículo 6 del primero!), entraña el riesgo de que el ingenio nacional termine por aplicar a estas leyes un calificativo ridículo que las haga desmerecer en la consideración que les es debida. Es cierto que el empleo de esta terminología es muchas veces obligado, pero también lo es que su uso superabundante podría reducirse en muchos casos.

Pero no se trata solo de cuestiones de apariencia. Nada más lejos de mi intención que minusvalorar la importancia de las tecnologías de archivo y comunicación on line, ni negar la aspiración de una Administración sin papeles. Pero esta es una realidad que se va paulatinamente consiguiendo sin necesidad de norma jurídica alguna (como ha sucedido en el mundo de la empresa privada) y que llegará por sus pasos naturales, sin recordatorios insistentes que solo sugieren la falsa imagen de una Administración que acabara de descubrir el procesador de textos y el e-mail y se apuntara con entusiasmo infantil a las delicias de la juguetería electrónica. Y menos aceptable es aún que la "electronización" intente imponerse a los ciudadanos manu militari, como el PLPAC hace y luego advertiré. 
Debo emprender a continuación un examen analítico de las normas de los proyectos que merecen un comentario crítico. Lamentablemente — bien hubiera deseado que no fuera así-, su número es muy amplio, y su exposición razonada exigiría disponer de un espacio que una publicación de esta naturaleza no permite; de ahí que su relato haya de ser necesariamente telegráfico, en perjuicio de la debida justificación y explicación de las afirmaciones que se hacen y, por supuesto, de la moderación del lenguaje; la concisión impone en muchos casos el empleo de términos muy vivos que resalten adecuadamente la importancia de los defectos sobre los que pretende llamarse la atención. Pido de antemano disculpas por los excesos en que pueda incurrir.

No es fácil, por otra parte, sistematizar el análisis de todos estos preceptos: como no me resulta adecuado ni digno seguir el orden numérico que estas normas tienen en los respectivos proyectos, los he agrupado en dos bloques: primero, el de las reformas que los textos introducen en el derecho positivo vigente; y segundo, el de las que podríamos Ilamar no-reformas, las regulaciones en vigor que, desde mi punto de vista, hubieran merecido una reconsideración o modificación, pero que los proyectos no abordan.

\section{LAS INNOVACIONES}

\section{A) Errores, ambigüedades, incertidumbres}

No son pocos los preceptos de este proyecto de ley que suscitan al lector una intensa perplejidad.

a) En ocasiones, tal perplejidad puede ser debida a una defectuosa redacción de las normas. Mencionaré unas cuantas.

- Para empezar, una cuestión de apariencia teórica, que surge de la lectura del artículo 2.4, tanto del PLRJSP como del PLPAC. De ambas normas se deduce que las Universidades públicas, que se enumeran como parte del llamado sector público institucional, no tienen la consideración de Administraciones Públicas, lo que produce una fuerte extrañeza. La exclusión de determinados entes públicos de la categoría de Administraciones Públicas tiene una cierta lógica en el ámbito de la legislación de contratos del sector público; pero no se advierte cuál pueda tener en el escenario del procedimiento administrativo común y del régimen jurídico de las Administraciones. El hecho de que, conforme a lo que dispone el apartado 2.c) de ambos artículos, las Universidades se rijan por su normativa específica y supletoriamente por los preceptos de estas dos leyes, no dice nada en contra de su naturaleza intrínseca de Administraciones, pues la misma previsión se hace en el PLRJSP respecto de Puertos del Estado (disposición adicional duodécima) o la Agencia Estatal de Administración Tributaria (disposición adicional decimoséptima), sin que ninguna norma les prive, como en el caso de las Universidades, de la condición de Administraciones Públicas. Quizá estos preceptos tengan una finalidad razonable, que se escapa al lector, y que debiera explicitarse; en otro caso, sería preferible su supresión.

- Una incertidumbre similar produce el artículo 37 del PLPAC, que, tras enunciar correctamente en su apartado 1 el principio de inderogabilidad singular de los reglamentos, incurre en un notorio exceso verbal en su apartado 2, al vaciar - al menos, aparentemente- de contenido la clásica distinción entre actos nulos de pleno derecho y anulables que se conserva en los artículos 47 y 48 . No es ni puede ser cierto, evidentemente, que las resoluciones administrativas que vulneren lo establecido en una disposición reglamentaria sean en todo caso nulas (además de las que incurran en alguno de los supuestos de nulidad de pleno derecho); es seguro que el precepto quiere expresar otra idea; pero ésta no se deduce en absoluto de su texto.

- El artículo 24.2 del PLPAC añade, a la regla no cuestionada del actual artículo 43.2 de la Ley 30/1992 ("la desestimación por silencio administrativo tiene los solos efectos de permitir a los interesados la interposición del recurso administrativo o contencioso-administrativo que resulte procedente"), un inciso final difícilmente comprensible: “... salvo que el acto devengue consentido y firme de acuerdo con lo previsto en el artículo 110". En primer lugar, es imposible que un acto presunto pueda quedar consentido y firme, ya que podrá ser recurrido en cualquier momento (artículos 122.1 y 124.1); y el artículo 110 del proyecto (actual artículo 106 de la Ley 30/1992) no se refiere a los actos consentidos. Este inciso es desconcertante, y debiera desaparecer.

- Y en la misma línea se mueve el artículo 16.1 del PLPAC, que da un distinto tratamiento al asiento en los registros de los documentos que se presenten en ellos (que es preceptivo), y a la anotación de las salidas de los documentos oficiales, que parece puramente facultativa ("se podrán anotar"). Quizá se trate de 
una expresión defectuosa, pero me parece que no es discutible que todos los documentos que salgan de una Administración deben hacerlo precisamente a través del registro, si es que pretende darse carácter oficial y formal, y seguridad, a tales comunicaciones.

b) En otros casos, la perplejidad que suscitan algunos artículos se debe a las lagunas que presentan.

- Es el caso, en primer lugar, del artículo 5.7 del PLPAC, que prevé que "las Administraciones Públicas podrán habilitar con carácter general o específico a personas físicas o jurídicas autorizadas para la realización de determinadas transacciones electrónicas en representación de los interesados". Aparte de lo conveniente que sería aclarar el incierto concepto de "transacciones electrónicas" (que parece referirse a la posibilidad de realizar transferencias monetarias entre ciudadanos y Administraciones), lo que es notorio es que esta posibilidad no puede concederse en ningún caso por las Administraciones, sino por los ciudadanos que otorgan su representación a otros; si lo que se quiere decir es que, para realizar pagos o cobros se necesita, además de la representación, una habilitación específica de la Administración, debiera decirse así; o, si no lo fuera, aclarar lo que quiere decirse.

- Es, también, el caso del artículo 6 del PLPAC, relativo a los registros de apoderamientos (el adjetivo “electrónico", reiterado hasta la saciedad en este artículo, sobra por completo), que es sumamente impreciso en cuanto al concreto registro en que han de inscribirse los poderes, cuando éstos habilitan para actuar ante más de una Administración pública: ¿ha de hacerse en todos los de las respectivas Administraciones, o basta hacerlo en el registro del Estado?

- Tampoco se aprecia prima facie cuál sea el supuesto añadido por el apartado 1.g) del artículo 22 del PLPAC como causa de suspensión del cómputo del plazo máximo para resolver y notificar. No es notorio, sencillamente, en qué casos es indispensable la obtención de un previo pronunciamiento jurisdiccional para la resolución de un procedimiento administrativo: quizá se refiera a la necesidad de obtención de una sentencia penal en los procedimientos de declaración de nulidad de actos constitutivos de delito, o de declaración de una relación jurídico-privada (por ejemplo, de propiedad). Pero el precepto es ambiguo y bien merecería un esclarecimiento.

- Mención especial merece la leve reforma que se hace en el artículo 22.1.d) del PLPAC respecto del texto que hoy se halla en el artículo 42.5.c) de la Ley 30/1992, según el cual la solicitud de informes preceptivos produce la interrupción del cómputo del plazo máximo para resolver. El PLPAC suprime, acertadamente, el incomprensible adjetivo de "determinantes"; pero el resultado de la reforma es incongruente. Los informes que sea preceptivo solicitar en un procedimiento son trámites cuya duración legal o previsible debe tomarse en cuenta a la hora de fijar la duración máxima de dicho procedimiento, porque forman parte natural y obligada del mismo; es absurdo considerarlos como un motivo de prolongación artificial de su tramitación. En el mejor de los casos, la previsión contenida en este precepto podría mantenerse solo respecto de los informes estrictamente vinculantes que hayan de ser emitidos por órganos de una Administración distinta.

C) En un plano práctico, el ejemplo paradigmático de la confusión se encuentra en los artículos 41 a 44 del PLPAC, relativos a la práctica de las notificaciones, que resultan de imposible comprensión racional con la mezcla que operan de las notificaciones por correo, en persona o mediante agente, o por correo electrónico; cada una de las cuales debiera regularse por separado y precisando con la máxima claridad en qué casos proceden, en qué lugares físicos o electrónicos han de realizarse ${ }^{4}$, el régimen de rechazo y los específicos efectos que en cada supuesto se producen. Pocos preceptos del proyecto son tan manifiestamente mejorables en su redacción como los mencionados.

d) Suscita igualmente perplejidad el que el PLRJSP, al efectuar la regulación de los órganos colegiados, mencione la figura del Presidente de cada órgano solo en los preceptos referidos a los órganos colegiados en la Administración General del Estado (artículos 19 y siguientes); mención que se halla por completo ausente de los artículos 15 a 18, que establecen normas para los órganos colegiados de todas las Administraciones Públicas. Parece poco discutible que una cierta regulación de la presidencia debe formar parte de las normas comunes a la organización de todas las Administraciones; y así se evitarían errores garrafales como el que comete el párrafo tercero

4 Es imposible saber, por ejemplo, si las notificaciones electrónicas podrán realizarse en cualquier dirección que elija el destinatario (así, en un gmail.com o yahoo.com personal) o en una específica que imponga la Administración; tampoco cabe adivinar si lo que se remite al correo del ciudadano es una notificación en forma (esto es, un mensaje con el correspondiente attachment o documento adjunto), o un mero aviso para que entre en la página de la Administración notificante y consulte o se descargue el documento a notificar (¿y en qué lugar, y con qué clave?); y tampoco se precisa si cada una de los miles de Administraciones que existen en España podrá imponer direcciones específicas para la recepción de sus mensajes, lo que haría físicamente imposible su consulta periódica. En general, y dicho de manera gráfica, toda la regulación de las comunicaciones electrónicas formales entre la Administración y los ciudadanos está muy verde. 
del artículo 17.2, que permite la celebración de "junta universal” (esto es, celebración de sesiones sin convocatoria previa cuando se hallen presentes todos los miembros del órgano), sin la asistencia del presidente.

e) En la regulación que el PLRJSP hace de los órganos colegiados se encuentra alguna innovación digna de ser mencionada, por lo discutible. Me refiero a la admisión general de celebración de sesiones de órganos colegiados mediante correo electrónico o audioconferencia. Es innecesario decir que estos medios de comunicación presentan gravísimas limitaciones frente a las sesiones presenciales, y que solo deberían poder ser utilizados, sin mengua del principio de colegialidad efectiva, para reuniones muy simples, con un número muy reducido de personas y para tratar cuestiones muy específicas. Es cierto que las sesiones presenciales obligan a ajustes de agenda y a desplazamientos muy penosos en grandes ciudades; pero no lo es menos que las posibilidades efectivas de comunicación en una audioconferencia son escasísimas, por la confusión y superposición de voces; privando, además, de lo invaluable de la proximidad física. Quienes por razones profesionales tenemos que celebrar diariamente varias conference-call sabemos bien de las confusiones e incertidumbres que producen, que luego tienen que ser corregidas mediante entrevistas personales. Estas posibilidades se reducen aún más en el empleo del e-mail, como es obvio; todo lo cual aconsejaría la autorización de estos medios con un carácter fuertemente restrictivo, en la línea que antes apunté.

\section{B) Reformas desafortunadas}

Oscuridades y confusiones aparte, el proyecto introduce diversas reformas que, desde la perspectiva de los ciudadanos, merecen un juicio claramente desfavorable, por razones muy diversas. Las expondré en un orden de gravedad creciente.

\section{Régimen de identificación de los ciudadanos}

En el orden de las cargas que se imponen gratuitamente a los ciudadanos, cabe mencionar, en primer lugar, la innecesaria sofisticación que se establece para el régimen de identificación de los ciudadanos ante las Administraciones Públicas (artículos 9 a 12 del PLPAC), mediante sistemas de firma o sello electrónicos, que solo muy excepcionalmente utilizan las personas físicas. Sin negar que tales métodos de identificación puedan ser necesarios para actuaciones de una gran trascendencia, su generalización es sencillamente un exceso innecesario. En España se realizan diariamente transacciones monetarias entre particulares por importe de decenas de miles de millones de euros mediante tarjetas de crédito, sin especiales problemas de identificación, y no hay razón para que las Administraciones no empleen de modo generalizado algún sistema equivalente [que no se sabe bien si es el denominado "de clave concertada" al que alude el artículo 9.2, letra c)] para los trámites normales que las personas hemos de realizar con la Administración.

\section{Deber de conocer el código de identificación}

Más carente aún de justificación es la exigencia de hacer constar en los escritos dirigidos a las Administraciones el código de identificación del órgano al que están destinados [artículos 66.1.f) y 115.1.d) del PLPAC]; código que nadie conoce y que ni siquiera figura hoy en el magnífico Portal de la Transparencia. Comprendo las pequeñas dificultades prácticas que se suscitan a los funcionarios ante escritos dirigidos a órganos mal designados o identificados; pero es la Administración la que debe asumir esta carga, que está provocada por los constantes cambios en la denominación o competencias de sus diferentes órganos. Esta exigencia debiera desaparecer, sencillamente, o convertirse en puramente facultativa.

\section{Plazos fijados en horas}

Ha suscitado alguna sorpresa la novedad que aporta el artículo 30.1 del PLPAC, relativo a los plazos fijados en horas. He de confesar mi ignorancia acerca de en qué supuestos concretos se hallan establecidos tales plazos (que, sin duda, los habrá, ya que se regulan); pero me resulta chocante que para el cumplimiento de cualesquiera obligaciones por parte de los ciudadanos no se mantenga un cierto respeto hacia las horas naturales de descanso o sueño, ya que se declaran hábiles todas las horas del día y de la noche ${ }^{5}$, desconociendo la tradición inveterada que hoy se plasma en el artículo 130.3 de la Ley de Enjuiciamiento Civil ("Se entiende por horas hábiles las que median desde las ocho de la mañana a las ocho de la tarde, salvo que la ley, para una actuación concreta, disponga otra cosa").

\section{Deber de comunicación electrónica}

Mucho más seria y cuestionable es la obligación que se impone a determinados colectivos y personas físicas de relacionarse electrónicamente con la Administración (artículo 14.2 del PLPAC): un precepto, lamento decirlo,

5 Salvo, por cierto, los sesenta segundos que median entre las 23:59 horas y las 00:00 del día siguiente. 
que parece desconocer la realidad social española, en lo que se refiere al uso de medios informáticos de trabajo y, sobre todo, de acceso a internet. Las entidades con o sin personalidad jurídica son mucho más que las sociedades del Ibex; son, también, cientos de miles de pequeñas sociedades familiares o comunidades de bienes tras las que no hay más que personas físicas carentes de organización alguna, cuyo grado de informatización no va mucho más allá que el manejo del Word o, en algún caso, de algunas hojas Excel muy sencillas; y no se piense en profesionales colegiados insertos en organizaciones como la que acoge al autor de estas páginas, sino también en el abogado o médico rural de la España profunda, dicho sea con el mayor afecto y respeto hacia ellos.

Y no se trata solo de las personas, sino de la red de comunicaciones: quienes nos comunicamos con las Administraciones a través de internet experimentamos diariamente la desesperación de las redes de wi-fi que no se detectan, o de las páginas web de Administraciones que se cuelgan con sospechosa frecuencia, o que conducen al usuario por links y vericuetos incomprensibles, modificados con frecuencia, o repletos de instrucciones solo comprensibles para su experto diseñador.

Lo que quiero decir, sencillamente, es que la comunicación normal y generalizada de los ciudadanos con las Administraciones españolas, en la forma en que el PLPAC diseña, es un objetivo que se conseguirá naturalmente en unos cuantos años, pero que es irreal e intolerable imponer de modo abstracto a la altura del tiempo que vivimos; sin prever medios para corregir los problemas técnicos de comunicación. En lugar de imponer, sin más, las obligaciones que establece el artículo 9, sería mucho más sensato que las Administraciones se fijaran un plan de informatización y comunicaciones dirigido a colectivos concretos, en colaboración con las asociaciones y colegios que los representan, y que, además, ofreciera incentivos a los usuarios que asumieran los objetivos que el plan establezca.

\section{Poderes y comparecencias electrónicas}

Me parece claramente desaconsejable el sistema de otorgamiento de poderes mediante comparecencia electrónica que establece el artículo 5.4del PLPAC. Otorgar un poder es un acto de relevancia suma, que exige inexcusablemente una comparecencia física, ante persona suficientemente competente y capaz de valorar la identidad del poderdante, el alcance del apoderamiento y el libre consentimiento; no ante cualquier empleado público carente de cualificación. No se ha podido inventar un procedimiento más seguro que el otorgamiento de poder ante notario, que es el que (no desde luego por rutina) utilizamos todos; y, como no defiendo en este caso ningún interés corporativo, he de decir que me parece incomprensible que el proyecto no mencione expresamente esta modalidad de apoderamiento.

\section{Supuestos generales de producción de silencio negativo}

Mucho más preocupante resulta la innovación que se introduce en los supuestos generales que dan lugar al efecto desestimatorio del silencio. El artículo 24.1, párrafo segundo, del PLPAC añade, a los ya existentes de ejercicio del derecho de petición, y a los procedimientos cuya estimación tuviera como consecuencia que se transfirieran al solicitante o a terceros facultades relativas al dominio público o al servicio público, así como los de responsabilidad patrimonial, el de los procedimientos que "impliquen el ejercicio de actividades que puedan dañar el medio ambiente". No entro a valorar la consistencia objetiva de este supuesto, sino los problemas continuos a que puede dar lugar la aplicación de un supuesto definido tan genérica y abstractamente, con el riesgo de que la regla general del silencio positivo se convierta de facto en negativo: ¿es que hay alguna actividad, aparte del pensamiento puro, que no sea susceptible de causar algún daño al medio ambiente?

Esta cuestión de la regla general de los efectos del silencio exigiría, a mi juicio, una reflexión pausada, hecha al margen de cualquier reforma legislativa general. El establecimiento del silencio positivo como norma fue un atrevimiento elogiable de los autores de la Ley 30/1992 (uno de los pocos: luego aludiré a otro no menos relevante), que cayó como una bomba en los medios funcionariales españoles, que se han preocupado de desnaturalizarlo sistemáticamente; como se hizo con la conocida Disposición Adicional Vigesimonovena de la Ley 14/2000, de 29 de diciembre, de medidas fiscales, administrativas y del orden social, entre otras muchas normas que restablecieron analíticamente el régimen general de silencio negativo. En la actualidad, el principio de silencio positivo que confirma el artículo antes citado no pasa de ser, en términos cuantitativos, más que una excepción; por lo que añadirle un nuevo pretexto para diluirlo en mayor grado me parece innecesario.

\section{Obligaciones de colaboración de los ciudadanos}

El artículo 18.1 del PLPAC modifica en un sentido restrictivo el vigente artículo 39.1 de la Ley 30/1992: se añade al texto de éste ("Los ciudadanos están obligados a facilitar a la Administración informes, inspecciones y otros actos de investigación sólo en los casos previstos por la Ley”) que "a falta de previsión expresa, facilitarán a la Administración los informes, inspecciones y otros actos de investigación que requieran para el ejercicio de sus com- 
petencias, salvo que la revelación de la información solicitada por la Administración atentara contra el honor, la intimidad personal o familiar o supusieran la comunicación de datos confidenciales de terceros de los que tengan conocimiento por la prestación de servicios profesionales de diagnóstico, asesoramiento o defensa, sin perjuicio de lo dispuesto en la legislación en materia de blanqueo de capitales y financiación de actividades terroristas".

La determinación de los supuestos en los que los administrados están obligados a colaborar con la Administración en el ejercicio de las competencias de ésta es una cuestión crucial que no puede resolverse de un modo tan escueto y ambiguo, empleando expresiones de sentido incierto como "facilitar" (que no se sabe bien si alude a la entrega de objetos o documentos, o a no oponer obstáculos injustificados a la acción administrativa), ni mezclando la colaboración respecto de terceros con la referida a las actividades propias. La legislación española no solo continúa partiendo de la presuposición de que los ciudadanos debemos realizar todas las actividades que la Administración nos requiera en orden a facilitar sus tareas, sino que, en diversas ocasiones, ha convertido la colaboración en un deber jurídico cuyo incumplimiento es sancionable como una infracción autónoma o como una causa determinante de un mayor grado de culpabilidad. Por más generalizada que esté esta práctica, es literalmente intolerable que las normas jurídicas amparen al presunto delincuente en su derecho a mentir paladinamente a la policía o a los jueces, y consideren este derecho como una infracción cuando el ciudadano no delincuente se ve incurso en una actuación administrativa (también sancionadora). Toda esta temática exige, como tantas otras, un debate público y abierto que permita llegar a conclusiones meditadas. El artículo 39.1 de la Ley 30/1992, con su añadido del PLPAC, no es admisible en un Estado que se pretende de Derecho.

\section{Mutación del instituto de las actuaciones previas}

Hasta 1992, la figura de las actuaciones previas a la iniciación del procedimiento administrativo no suscitó una atención especial: importada del procedimiento disciplinario de la función pública, su fundamento prudencial parecía evidente, habida cuenta de los daños colaterales que produce por si la tramitación de cualquier procedimiento administrativo de finalidad presuntamente limitativa. Quizá por ello, el artículo 69.2 de la Ley 30/1992 le dedicó un precepto tan escueto como neutro.

A partir de la fecha indicada, sin embargo, la funcionalidad del instituto se ha transformado como consecuencia de la imposición del plazo máximo para resolver y notificar, convirtiéndose —en muchos casos—en una modalidad fraudulenta de prolongación artificial ex ante de los plazos de resolución máxima de los procedimientos iniciados de oficio (y amenazados, por tanto, de caducidad): el procedimiento se inicia de facto antes de su incoación formal, y durante esta fase previa, que no computa en el plazo máximo, se producen todo tipo de actividades de instrucción, incluidas las probatorias (que deberían realizarse una vez abierto el procedimiento); las cuales $-\mathrm{y}$ aquí radica el problema - se llevan a cabo sin la debida participación de los interesados. Esta mutación posee una extraordinaria gravedad en el ámbito de los procedimientos sancionadores, que, cuando se inician formalmente, el imputado se encuentra ante todo un aparato probatorio completo y consolidado, frente al que no existen apenas posibilidades de contradicción y defensa.

Y esta alteración de la naturaleza del instituto viene a ser confirmada implícitamente por el PLPAC, cuyo artículo 55, añadiendo en su apartado 2, y con referencia específica a los procedimientos sancionadores, que las actuaciones previas "se orientarán a determinar, con la mayor precisión posible, los hechos susceptibles de motivar la incoación del procedimiento, la identificación de la persona o personas que pudieran resultar responsables y las circunstancias relevantes que concurran en unos y otros". La determinación de los hechos es el objeto principal de todo procedimiento sancionador (junto con la autoría y la responsabilidad) y, por tanto, no puede ser realizada fuera del mismo, con carácter anticipado y sin participación del presunto culpable. Es necesario restituir la figura de las actuaciones previas a su función típica de apreciación liminar de la existencia real de los hechos y de la conveniencia de iniciar o no un procedimiento, sin avanzar los trámites de éste.

\section{Generalización del sistema de clemencia}

En la cumbre de las innovaciones desafortunadas - a mi juicio— se encuentra, finalmente, la generalización del sistema de clemencia a favor de los denunciantes (artículo 62.3 del PLPAC), importado del régimen tributario de los años ochenta y, más próximamente, de la legislación de defensa de la competencia, y aplaudido de forma irresponsable.

Aunque esta cuestión exigiría un tratamiento mucho más extenso que el que aquí puede dársele, debe recordarse brevemente que esta institución no tiene su origen, como a veces se dice, en el ordenamiento comunitario; es una importación del sistema judicial norteamericano, cuya brutalidad típicamente medieval le hace estar aún a años luz del grado de sofisticación y respeto que tienen los procedimientos administrativos y judiciales de la vieja Europa. La delación fue, durante siglos, un medio de represión típico de los sistemas penales del Estado precons- 
titucional, una técnica de dominación mediante el terror y la desconfianza recíproca entre los súbditos, y que los Estados contemporáneos han asumido con entusiasmo como un método expeditivo de suplir sus carencias en la capacidad de investigación pública de las conductas ilegales; despreciando, como daño colateral, su empleo privado como un aliviadero de los impulsos oscuros de venganza personal o de guerra económica despiadada. Quienes trabajamos profesionalmente en asuntos de defensa de la competencia tenemos cumplida constancia del empleo de la denuncia como un procedimiento dirigido exclusivamente a instrumentalizar el aparato del Estado con el exclusivo fin de causar daño o desprestigio a competidores legítimos dotados de mayor poder económico. La idea de la "guerra total" no fue una invención de los contendientes en la segunda gran guerra, sino un arraigado modo de ser de las empresas estadounidenses del último tercio del siglo XIX, al que los Estados han prestado una acogida sumamente interesada.

Es gravísimo, dicho sea sin ambages, que un proyecto de ley tan minucioso en la protección de los derechos de los ciudadanos y de la paz social, asuma un procedimiento primitivo de represión, que choca con una larga tradición de repulsa social hacia el mismo: no en balde padecimos por estos pagos, durante más de trescientos años, un horror llamado Tribunal del Santo Oficio, uno de cuyos instrumentos favoritos era precisamente la delación. La reforma que pretende introducir este artículo 62.3 solo puede merecer el rechazo general, y suscitar el ruego de que sea rápidamente suprimido y olvidado.

\section{LAS DEFICIENCIAS NO CORREGIDAS}

El activismo que los proyectos muestran en introducir reformas cuestionables (siempre desde la perspectiva del ciudadano) se completa y contrasta con una sorpendente pasividad en el emprendimiento de modificaciones de la Ley 30/1992 que la doctrina viene reclamando desde hace décadas. Es cierto que el proyecto aborda algunas de importancia no desdeñable; pero, aparte de tratarse de aclaraciones tomadas de la doctrina jurisprudencial, más que de novedades auténticas ${ }^{6}$, su relevancia no tiene punto de comparación con las cuestiones que permanecen intactas, y que son muy numerosas. Habremos de exponerlas, pues, telegráficamente, comenzando por las de menor entidad.

\section{A) Las reformas cruciales nunca abordadas}

\section{La precisión del régimen de la caducidad de los procedimientos iniciados de oficio}

Son abundantes las reflexiones que en el plano doctrinal se han hecho sobre el instituto de la caducidad, denunciando las numerosas prácticas y pretextos dirigidos a desnaturalizarlo7 en el sentido de reducir su ámbito de aplicación (así, en los llamados actos administrativos de doble efecto) y de posibilitar la reapertura de los procedimientos caducados tantas veces cuantas permitan los plazos de prescripción; y no tiene justificación que el artículo 25.1.b) del PLPAC mantenga intacta la redacción del artículo 44.2 de la Ley 30/1992, desoyendo el clamor continuo que suscitan estas cuestiones.

Es cierto que se trata de un tema arduo. Junto con el régimen de silencio positivo (teóricamente) general en los procedimientos iniciados por los interesados, la caducidad se convirtió en una de las bestias negras de ciertos sectores de la burocracia española, que consideraban secularmente como un derecho inalienable emplear en la tramitación de los procedimientos tanto tiempo como se estimara necesario, desconociendo el perjuicio que ello causa a los ciudadanos. Pero la conquista que se implantó en 1992 no tiene marcha atrás, y sería altamente conveniente que el legislador ofreciese una regulación algo más equilibrada y completa de este instituto; eso sí, suprimiendo la incalificable posibilidad de reapertura, dentro del plazo de prescripción, de los procedimientos caducados, que es sangrante para cualquier ciudadano.

\section{El eterno problema de las "notificaciones del mes de agosto"}

Hace más de un cuarto de siglo que el profesor GONZÁLEZ PÉREZ expresara el rechazo colectivo a esta inadmisible práctica, que continúa utilizándose sistemáticamente; con frecuencia, con el indisimulado objetivo de provocar la pérdida de plazos de los destinatarios de los actos administrativos. Las notificaciones realizadas en

6 Por ejemplo, el cómputo de los plazos fijados en meses o años (artículo 30.4), o la apertura indefinida del plazo para recurrir desestimaciones por silencio, ya antes aludida. Ha de reconocerse, en contraste, la importancia práctica de la regla de la inhabilidad de los sábados (artículo 30.2), tomada del ámbito procesal, que no solo proporciona comodidad, sino ante todo seguridad jurídica. Hoy por hoy, una gran parte del colectivo de abogados españoles desconoce que, en vía administrativa, ese día de la semana no es inhábil, como ocurre en los procesos de toda índole. Y es una lástima que, puestos a tomar instituciones del mundo procesal, no se haya acogido la institución del día de gracia que prevé el artículo 135.1 de la Ley de Enjuiciamiento Civil; quizá haya pesado la vieja idea de que los regalos, como los que se hacen a los niños, hay que dosificarlos con moderación.

7 Entre otras diversas aportaciones, vid. J. A. LÓPEZ PELLICER, La caducidad del procedimiento administrativo sancionador: ¿puede reabrirse y tramitarse otro si la infracción no ha prescrito?, Actualidad Administrativa n. ${ }^{\circ} 42$ (noviembre de 1999); V. AGUADO I CUDOLÀ, Prescripción y caducidad en el ejercicio de potestades administrativas, Madrid, Marcial Pons, 1999; J. A. SANTAMARÍA PASTOR, Caducidad del procedimiento (art. 44.2 LRJAP), RAP 168 (2005), p. 7 ss.; F. LÓPEZ RAMÓN, La caducidad del procedimiento de oficio, RAP 194 (2014), p. 11 ss. 
períodos vacacionales o prevacacionales son una vergüenza de nuestra cultura administrativa que se resiste a desaparecer pese a su manifiesta carencia de justificación. El derecho a vacaciones no puede ser entendido simplistamente como un derecho a la ausencia del puesto de trabajo; es un derecho a desconectar de todo orden de preocupación cotidiana, por razones de tranquilidad y de higiene mental, que debe comprender también a las actuaciones de la Administración. No hay vacación ni descanso digno de tal nombre si cualquier ciudadano ha de proveer a la presencia en su domicilio de una persona que reciba las notificaciones que se le cursen durante su ausencia, o, como ahora anuncia el proyecto, si debe estar atento a su correo electrónico para recibir todo tipo de malas noticias de las Administraciones con las que se relaciona, soportando al tiempo los reproches de sus familiares.

Es de lamentar que el PLPAC no aborde esta nada nimia cuestión; más aún, cuando no debe tratarse de un olvido, como acredita el que su artículo 43.2 confirme la norma según la cual se entenderá rechazada toda notificación electrónica a cuyo contenido no se haya accedido en el plazo de diez días desde su puesta a disposición. Quizá sería suficiente el que se previera que, sin perjuicio de que la notificación pueda realizarse en cualquier momento, los plazos que se inicien con ella no empezarán a computarse sino a partir del primer día hábil siguiente al período vacacional que se establezca (el citado mes de agosto o el equivalente que el ciudadano indique a su Administración respectiva).

\section{El engañoso efecto liberalizador de las declaraciones responsables y de las actividades comunicadas}

Las deficiencias que ofrece el artículo 69 del PLPAC (que reproduce el texto del vigente artículo 71 bis de la Ley 30/1992) han sido también reiteradamente denunciadas, y es decepcionante que el proyecto no aborde su reforma. Esta deficiencias no se refieren a cuestiones técnicas de orden más o menos menor, sino a la carencia en un modelo presuntamente liberalizador de piezas capitales, como son las potestades de que dispone la Administración para corregir y sancionar las infracciones legales en que hayan incurrido los declarantes o comunicantes y, sobre todo, el plazo para utilizarlas. En ausencia de estas regulaciones, las declaraciones responsables y las actividades comunicadas se convierten en un título de habilitación indeseable para cualquier operador económico sensato, que jamás procederá a realizar cualquier inversión mínimamente cuantiosa sin la garantía de que su proyecto no podrá ser enervado y clausurado por la Administración en el momento temporal en que ésta tenga por conveniente, y siempre en base al real o supuesto incumplimiento de requisitos legales más o menos discutibles.

Es cierto que la inercia de los sistemas administrativos de intervención previa (vía autorización) es aún muy fuerte, y que, pese a los esfuerzos desplegados por las Leyes 17 y 25/2009, de transposición de la Directiva de Servicios, el ámbito de aplicación de los regímenes de declaración responsable y comunicación previa es aún muy reducido; pero no hay que descartar que los afanes liberalizadores de la normativa comunitaria obliguen en un futuro próximo a ampliar considerablemente dicho ámbito, lo cual sería una catástrofe para los operadores económicos que pretendan desarrollar su actividad en sectores objeto de una regulación técnica minuciosa, densa y compleja. En su simplista configuración actual (sustitución de la autorización previa por una declaración responsable), el modelo supuestamente liberalizador constituye un fraude literal para sus usuarios privados, a los que se condena a una situación de inseguridad mucho más grave que el que pretende sustituirse. Es verdad que el régimen de autorización previa supone un freno temporal a la iniciativa económica: pero no debe olvidarse que el empresario compra, a cambio de la demora, la seguridad de su inversión, que queda amparada por un acto administrativo. Un sistema de comunicaciones responsables solo es aceptable si es acompañado, simultáneamente, por una desregulación profunda de la actividad, que minimice el riesgo de intervenciones ex post más o menos justificadas o arbitrarias.

Y es necesario ser también muy claro en la valoración del argumento utilizado para la extensión del sistema de declaraciones responsables, según el cual se elimina un incentivo a la corrupción. Dicho argumento es absolutamente falaz: como demuestra la experiencia de países que no es preciso mencionar, el cambio del régimen de autorización por el de declaración responsable solo produce un desplazamiento del nivel orgánico en el que la corrupción puede tener lugar: ya no opera en el de las personas titulares de la competencia para emitir el acto administrativo de autorización, sino en el de los empleados públicos que llevan a cabo la comprobación a posteriori e in situ del ajuste de la actividad a la reglamentación correspondiente, los cuales, por su menor nivel, son más fácilmente corruptibles.

\section{El problema de los actos dictados en ejecución de reglamentos anulados}

La legislación española de procedimiento administrativo ha huido históricamente de abordar la espinosa, pero muy relevante cuestión de la comunicación de invalidez de los reglamentos a los actos dictados a su amparo: la vigente Ley 30/1992 la trata de pasada en un lugar recóndito (un inciso del artículo 102.4), una línea que el PLPAC 
mantiene en su artículo 106.4, que es, además, manifiestamente inadecuado, ya que la nulidad de los reglamentos casi nunca tiene lugar en virtud de una revisión de oficio, sino solo en vía jurisdiccional.

Por lo demás, la solución que se da al tema (la nulidad del reglamento afecta solo a los actos cuya impugnación se haya iniciado y se halle en curso) es disfuncional, en cuanto provoca nubes de recursos que colapsan el funcionamiento de los órganos jurisdiccionales; y es, además, cínica, puesto que la Administración cuenta siempre con el margen de beneficio que le proporciona el porcentaje de actos no recurridos o recurridos tardíamente.

Quizá una reforma general y apresurada no sea el escenario adecuado para plantearse en profundidad esta cuestión; pero a medio plazo será inexcusable suscitarla, porque las situaciones injustificadas suelen dar lugar, de modo inopinado a directrices jurisprudenciales imprevisibles y radicales.

\section{El inmovilismo del sistema de recursos}

Sorprende también la resistencia que un sistema tan desprestigiado como el de recursos administrativos se mantenga incólume tras esta reforma, que solo modifica, como vimos, el plazo de recurso contra desestimaciones por silencio, haciendo oídos sordos a lo que es un auténtico clamor desde hace medio siglo.

El régimen de recursos administrativos ordinarios no es sostenible ni defendible; y esto es algo que las Administraciones saben y comparten, pero que se mantiene contra viento y marea; y este empecinamiento solo es explicable por intereses puramente tácticos, indeclarables por indefendibles. Los recursos administrativos ordinarios hace mucho tiempo que dejaron de ser un método de autocontrol de la Administración, puesto que se resuelven de manera mecánica y sin preocupación por la garantía de la legalidad; y jamás han sido un instrumento ágil y barato de resolución de los conflictos con los sujetos privados, ya que el porcentaje de los que son estimados es absolutamente despreciable.

Es tan duro como obligado reconocer que solo el interés de la Administración en disponer de un plazo suficiente para ejecutar cumplidamente sus decisiones, sin control judicial, explica el empecinamiento en mantener el carácter preceptivo de la alzada, así como el que este recurso tenga un plazo de silencio tres veces superior al del recurso de reposición (la disparidad no puede tener otra razón de ser: ¿o es que se tarda más en resolver un recurso de alzada que otro de reposición?). Que el obligado recurso de alzada carece hoy de justificación objetiva es, por lo demás, algo que la propia Administración comparte: así lo demuestra, a mi juicio, la proliferación de disposiciones legales y reglamentarias que lo suprimen tácitamente, incluyendo a múltiples actos administrativos dentro de la categoría de los que ponen fin a la vía administrativa (aunque sean dictados por órganos que disponen de superiores jerárquicos); y es también indicio de ello la propia decisión del PLPAC, que suprime sin más las reclamaciones previas a la vía judicial civil y laboral.

Algo semejante cabe decir del incomprensible régimen de prolongación de los efectos de la suspensión del acto impugnado en vía de recurso administrativo (artículo 111.4, párrafo tercero, de la Ley 30/1992). Este precepto es, sin duda, el menos afortunado de todos los rectificados en la reforma de 1999, que muy probablemente se vio obligado a "compensar" el atrevimiento de establecer un régimen de silencio positivo respecto de las solicitudes de suspensión formuladas en los recursos (por el mero transcurso del plazo de treinta días) con una enigmática regulación de la prolongación de sus efectos hasta la iniciación de la vía contenciosa, que da lugar a discusiones y forcejeos continuos y que el PLPAC mantiene intacta. Que estas deficiencias son reales lo demuestra el cuidado de que el proyecto ha hecho gala en la regulación de la suspensión de la ejecutividad de las resoluciones sancionadoras (artículo 90.3): una norma que, sin ser enteramente satisfactoria, es mucho más meditada que la que figura en el artículo 117.4 del PLPAC, y a la que bien podría haber servido como modelo.

Como todas las cuestiones que se analizan en este epígrafe, el régimen de recursos administrativos exige una revisión muy seria y equilibrada que no tiene más que dos soluciones alternativas: su mantenimiento, confiándose a órganos independientes semejantes a los ya establecidos en materia de contratos públicos (que están funcionando de manera bastante satisfactoria: artículos 40 y siguientes del texto refundido de la Ley de Contratos del Sector Público), o su definitiva y tantas veces reclamada conversión en trámites puramente potestativos.

\section{La asignatura pendiente de la confidencialidad}

Tampoco se aborda en el PLPAC, por fin, el cada día más acuciante tema de la confidencialidad de los datos e informaciones privadas en poder de la Administración y su polémica puesta de manifiesto en los procedimientos en los que tiene lugar un enfrentamiento entre operadores económicos privados, como son los de defensa de la competencia y, sobre todo, los de carácter contractual. La experiencia profesional revela que no pocas denuncias por reales o supuestas infracciones de la normativa de defensa de la competencia se realizan con la exclusiva finalidad de participar en el procedimiento sancionador y tener así acceso a los datos confidenciales de las empresas 
denunciadas que la CNMC les requiere en ejercicio de sus competencias. $Y$ tampoco es inusual que algunas empresas sin escrúpulos participen en licitaciones que no tienen posibilidad alguna de lograr, con objeto de impugnar la adjudicación e intentar tener acceso al contenido de las ofertas en el procedimiento de recurso ante el correspondiente tribunal de recursos contractuales: basta leer las resoluciones de dichos tribunales para percatarse de estas estrategias.

Como todos los restantes que estamos examinando, esta de la confidencialidad es una cuestión extremadamente ardua y de difícil solución, como lo demuestra el que el ordenamiento comunitario (donde es una cuestión cotidiana y recurrente) no haya acertado a apuntar criterios claros y satisfactorios; y ello quizá explica en que la legislación de procedimiento administrativa rehúya esta cuestión como el gato al agua. Es muy difícil, en efecto, cohonestar la protección de la confidencialidad de los datos económicos y el derecho de defensa de quienes se enfrentan en un procedimiento administrativo al titular de los datos, como lo es también compaginar el respeto a la vida privada y la libertad de información; $y$, desde luego, el autor de estas páginas no dispone de soluciones que pueda defender como inequívocamente satisfactorias. Pero ello no excusa a las Administraciones de intentar darle una salida razonable.

Y no se trata solo de la necesidad de garantizar la confidencialidad de los datos privados en los procedimientos competitivos, sino del riesgo intrínseco que conlleva la progresiva acumulación de informaciones estrictamente privadas en manos de las Administraciones, que éstas obtienen en los procedimientos autorizatorios o en su labor inspectora; son excepcionales en las Administraciones españolas los sistemas de protección de estos datos frente a las indagaciones ilícitas realizadas por terceros - con las normales complicidades internas-, como los muy depurados que utiliza la Agencia Estatal de Administración Tributaria, que quizá debieran generalizarse; sistemas que solo permitan el acceso a empleados públicos contados e identificados, y que dejen huella inequívoca de todo tipo de consultas. El tema es de una relevancia capital, y me parece sencillamente cínica la preocupación que todas las Administraciones (españolas y extranjeras) muestran por la acumulación de datos en manos de los grandes buscadores de internet, cuando muchas de ellas disponen de informaciones sobre la vida privada de sus ciudadanos y de la actividad de sus empresas mucho más extensa y detallada que la que reposa en los servidores de Google; y una información, desde luego, mucho más desprotegida, frente a accesos externos incontrolados e ilícitos, que la que obra en poder del gigante de Mountain View.

\section{B) Otras cuestiones de menor entidad}

\section{Las relaciones de procedimientos}

Las inobservancias palmarias y generalizadas por las Administraciones de las obligaciones que las leyes les imponen pueden ser explicadas; difícilmente pueden ser justificadas, salvo cuando se trate de obligaciones económicamente muy gravosas o técnicamente muy complejas; pero lo que no es admisible es que una ley reitere el mandato establecido en otra precedente, y sistemáticamente incumplida, sin prever reacción alguna a este incumplimiento.

Esto es lo que sucede, exactamente, con la obligación que pesa sobre todas las Administraciones de "publicar y mantener actualizadas en el portal web, a efectos informativos, las relaciones de procedimientos de su competencia, con indicación de los plazos máximos de duración de los mismos, así como de los efectos que produzca el silencio administrativo" (artículo 21.4 del PLPAC, que reproduce el artículo 42.2 de la Ley 30/1992). Son, literalmente, docenas las Administraciones que no proporcionan esta información, vital para muchos administrados; y el propio Estado, que sí la ofrece ${ }^{8}$, proporciona datos en muchos casos abundantes y de innegable interés práctico, pero entre los que no figuran, en muchas ocasiones, los de duración del procedimiento y sentido del silencio, únicos que el precepto antes citado exige.

No sería imposible forzar a las Administraciones al cumplimiento puntual de esta obligación, que no es costosa ni compleja. Bastaría con establecer la norma según la cual todos los procedimientos cuya información no figurase en las respectivas webs con sus datos legales completos se regirín por las normas generales y supletorias establecidas en los artículos 42.3 y 43.1 de la Ley 30/1992: esto es, con un plazo máximo de duración de tres meses y efectos de silencio positivo. La solución puede parecer radical; pero las desobediencias manifiestas y permanentes no admiten más que soluciones de este tipo.

\section{Los tratamientos desigualitarios}

La Ley 30/1992 contiene algunas disposiciones que establecen tratos discriminatorios en los derechos paralelos que se otorgan a las Administraciones y a los ciudadanos; discriminaciones que no responden a ninguna razón

8 Aunque en un lugar no excesivamente visible de su Punto de Acceso General: puede consultarse en http://administracion.gob.es/ pagFront/tramites/catalogo/catalogo.htm\#.VWNF6SWJi1s. 
objetiva o de interés público y que son, por ello, escandalosas. Dos son las más conocidas, que el PLPAC no elimina.

La primera de ellas, en el régimen de ampliación de plazos: una Administración puede autoconcederse una prórroga del plazo máximo para resolver de hasta el 100\% de la duración del mismo (artículo 42.6 de la Ley 30/1992; artículo 23.1 del PLPAC); pero si la prórroga es solicitada por el interesado en el procedimiento, su duración no puede exceder del 50\% del plazo previsto para el respectivo trámite (artículo 32.1) ${ }^{9}$. Esta diferencia es arbitraria, y debería ser corregida.

Y la segunda, bastante similar, se encuentra en la vergonzosa contradicción que se produce entre los artículos 47 y 63.3 de la Ley 30/1992, que el PLPAC mantiene en sus artículos 29 y 48.3: los plazos, indiscutiblemente, vinculan a los interesados en un procedimiento, de tal manera que su incumplimiento determina la pérdida del trámite (artículos 92.1 de la Ley 30/1992 y 95.2 del PLPAC) o la firmeza del acto que se impugna. Pero no vinculan a la Administración, pese a lo que dice enfáticamente el artículo 47 de la Ley 30/1992, ya que su artículo 63 continúa diciendo con el mayor desparpajo (desde 1958!) que "la realización de actuaciones administrativas fuera del tiempo establecido para ellas sólo implicará la anulabilidad del acto cuando así lo imponga la naturaleza del término o plazo"; en la práctica, y fuera de los supuestos de caducidad, casi nunca.

\section{La interdicción de la reformatio in pejus}

El artículo 88.2 del PLPAC reproduce literalmente el actual artículo 89.2 de la Ley 30/1992, cuya redacción dista mucho de ser afortunada. La prohibición de que la resolución final de un procedimiento agrave la situación del ciudadano que lo inició tenía, evidentemente la finalidad de eliminar la posibilidad de actuaciones "reconvencionales" de la Administración, que actuaran como un desincentivo de las solicitudes que hayan de dirigirse a ella. Pero lo cierto es que el inciso que sigue a esta prohibición posee el mismo efecto disuasorio que la posibilidad de una resolución in pejus: en nada tranquiliza al interesado solicitante que se le diga que la resolución que se dicte no podrá agravar su status inicial si acto seguido se le advierte que tal agravación podrá producirse en virtud de un nuevo procedimiento, incoado de oficio en base a las informaciones obtenidas en el inicial.

Este inciso final debería ser sencillamente suprimido por el tono intimidatorio que posee; y, también, porque es perfectamente innecesario, dado que nada impide a la Administración que incoe de oficio un nuevo procedimiento en base a las informaciones que haya podido obtener por cualquier vía, ni puede prohibírsele que lo haga.

\section{La prohibición de abstención}

El artículo 19.3.c) del PLRJSP mantiene una regla de la Ley 30/1992 que ya fue objeto de críticas tan duras como acertadas: me refiero a la prohibición que impone de abstenerse en las votaciones a "quienes por su cualidad de autoridades o personal al servicio de las Administraciones Públicas, tengan la condición de miembros natos de órganos colegiados, en virtud del cargo que desempeñan".

No hay razón alguna, en efecto, para considerar la abstención como una conducta reprobable, ya que abstenerse es una posición tan legítima y adecuada como emitir un voto positivo o negativo; significa, sencillamente, que el miembro del órgano no puede alcanzar una conclusión satisfactoria en el balance entre los factores positivos y negativos que puede tener un acuerdo, no pudiendo interpretarse como una muestra de desinterés o una dejación de funciones. Pero además, dicha prohibición choca frontalmente con el deber de abstención que se produce cuando se incurre en las situaciones que menciona el artículo 23 y, sobre todo, con la previsión que hoy figura en el artículo 17.6 del PLRJSP ("Cuando los miembros del órgano voten en contra o se abstengan, quedarán exentos de la responsabilidad que, en su caso, pueda derivarse de los acuerdos"). No tiene sentido prohibir la abstención en la adopción de un acuerdo cuando el miembro del órgano decide salvar su responsabilidad personal; entre otras razones, porque se le obliga indirectamente a votar en contra de un acuerdo que puede ofrecer aspectos positivos. La prohibición debería desaparecer.

\section{CONCLUSIÓN}

Toda valoración global de iniciativas complejas e importantes es inevitablemente arriesgada y parcial, y puede resultar objetivamente injusta. Pero creo que no cumpliría adecuadamente la tarea que se me encomendó si no la formulase.

En las páginas iniciales de este trabajo apunté un juicio positivo sobre la calidad técnica del proyecto, que debo reiterar. En lo que aportan de novedad, los dos proyectos revelan un buen hacer, un trabajo arduo y minucioso, una alta competencia técnica y una claridad en la redacción que es más de agradecer cuanto que más escasea en los tiempos actuales.

9 A lo cual podría añadirse la incalificable y muy generalizada práctica de no dar respuesta a las solicitudes de ampliación de plazos formuladas por los interesados (o de hacerlo cuando el plazo principal ha expirado ya). Sería lógico que la Ley previera que dicha falta de respuesta en plazo se entenderá como un otorgamiento tácito de la ampliación. 
Cuestión distinta es la relativa a la oportunidad y conveniencia de los proyectos. Por su escaso alcance innovador, me temo que estos proyectos — si es que llegan a aprobarse— no pasarán a la historia, por tratarse de operaciones normativas de refundición legislativa material, con diversas reformas micro que no afectan con intensidad a ninguna de las instituciones capitales de los temas que abordan. $Y$, por ello, su incidencia en el funcionamiento de la Administración y en el marco de relaciones de ésta con los ciudadanos puede llegar a ser insensible. Cabe preguntarse, entonces, si un número tan corto de modificaciones justifica el considerable esfuerzo de redacción y sistematización emprendido por los servicios de la Administración General del Estado; más aún, si su puesta en vigor puede justificar la notable incomodidad que supondrá para todos los juristas de derecho público el estudio y la retención de todos los contenidos de las nuevas leyes ( y — lo que no es nada irrelevante- si la reforma puede compensar la perturbación que genera el mero cambio de numeración de los preceptos ya existentes).

Menos favorable aún es el balance de mejoras que ofrece su contenido. De una parte, y como he tratado de razonar, la mayor parte de las modificaciones que se introducen al texto vigente de la Ley 30/1992 son, cuando menos, discutibles; no pocas, criticables; y unas cuantas, claramente rechazables. Sería exagerado afirmar que los textos provocan un empeoramiento cuantitativo y cualitativo considerable del derecho hoy en vigor; pero si a ello se añade la decisión de no abordar múltiples reformas cruciales y largo tiempo reclamadas, el resultado, en su conjunto, no puede considerarse satisfactorio. Como ya dije, hubiera preferido vivamente que mi valoración final fuera distinta: pero el deber de honestidad intelectual debe ponerse por encima del respeto y del aprecio que siento por las personas que han elaborado estos proyectos.

Pero, como no me gustan los finales infelices, debo añadir que ha sido un acierto de este gobierno poner encima de la mesa una reforma global de la Ley 30/1992, que buena falta viene haciendo; y espero y confío que, si los plazos no permitieran aprobar estos proyectos en la presente legislatura, sean retomados por el ejecutivo que salga de las urnas a finales del presente año; que sean sometidos a trámites de consulta menos formales que el de información pública (un trámite aparentemente muy democrático, pero que es la menos pública de todas las informaciones, porque solo llega al conocimiento de una minoría); y, sobre todo, que ofrezcan nuevos contenidos con los que se dé — por fin — respuesta a las reiteradas exigencias que la sociedad civil demanda de sus Administraciones. Tenemos una legislación de procedimiento y régimen jurídico aceptablemente buena; pero creo que nos merecemos, ya, una bastante mejor. 